\title{
ZONEAMENTO GEOAMBIENTAL NO OESTE DO RIO GRANDE DO SUL: UM ESTUDO EM BACIAS HIDROGRÁFICAS EM PROCESSO DE ARENIZAÇÃO
}

\section{Geoenvironmental Zoning in the west of Rio Grande do Sul: A study on Hydrographic Basins in sandy patch process}

\author{
Dionara De Nardin \\ Geógrafa, Mestre em Geografia (Análise Ambiental) - UFRGS \\ Porto Alegre/RS - Brasil \\ diodenardin@yahoo.com.br
}

Luís Eduardo de Souza Robaina

Docente do Departamento de Geociências da UFSM e do PPGEA/ UFRGS Laboratório de Geologia Ambiental - Universidade Federal de Santa Maria

Santa Maria/RS - Brasil lesrobaina@yahoo.com.br

Artigo recebido para publicação em 09/05/2010 e aceito para publicação em 09/11/2010

RESUMO: O presente artigo tem como tema o zoneamento geoambiental de bacias hidrográficas aftuentes do Rio Ibicuí, no sudoeste do Rio Grande do Sul. A metodologia empregada inclui mapeamentos temáticos, com o auxílio de SIGs (Sistemas de Informação Geográfica), e trabalhos de campo e de laboratório, que servem de base para o zoneamento. Os dados levantados indicam que as zonas de maior fragilidade ocorrem no Sistema Sanga da Areia, no qual se desenvolvem com frequência areais e voçorocas e onde se identificam os primeiros plantios de espécies arbóreas exóticas. Destaca-se a contribuição da vegetação nativa, sugerindo-se, de imediato, devido às pressões das monoculturas, a preservação da unidade butiá-anão, espécie endêmica do Bioma Pampa.

Palavras-chave: Zoneamento Geoambiental. Planejamento Ambiental. Arenização.

ABSTRACT: The present paper has as a theme the geoenvironmental zoning of hydrographic basin afluents of the Ibicui River, in the southwest of Rio Grande do Sul state. The methodology used includes thematic mappings with the aid of SIGs (Geographic Information Systems), field and laboratory works that serve as basis for the zoning. The data collected indicates yet that the zones of higher fragility occur in the Sanga da Areia System, where sand flats and gully erosion are frequently developed, and where the first plantings of exotic arboreal species are being identified. Stands out the contribution of the native vegetation, where it is immediately suggested, due to the pressure of monocultures, the preservation of the butiá-anão unity, endemic species of the Pampa Biome.

Keywords: Geoenvironmental Zoning. Environmental Planning. Sandy patch. 


\section{INTRODUÇÃO}

O presente artigo parte de reflexões contidas na dissertação de mestrado, na qual é apresentada uma série de levantamentos do meio natural e antrópico, integrando um zoneamento geoambiental de bacias hidrográficas do oeste do Estado.

A proposta de zoneamento geoambiental procura definir, através de uma abordagem sistêmica, as principais características ambientais indicadas pela fragilidade e potencialidade da paisagem em questão.

A metodologia sistêmica empregada busca conjugar conceitos de diversos meios científicos, visando resolver problemas, sob o ponto de vista da Teoria Geral de Sistemas. Aproximando-a da questão ambiental, Tricart (1977) afirma que o conceito de sistema é o melhor instrumento lógico disponível para estudar os problemas do meio ambiente, pois permite adotar uma atitude dialética entre a necessidade da análise e a necessidade contrária de uma visão de conjunto, capaz de ensejar uma atuação eficaz sobre esse meio ambiente. Para o autor, um sistema é um conjunto de fenômenos que se processam mediante fluxos de matéria e energia, os quais originam relações de dependência mútua entre os fenômenos. Portanto, o método sistêmico aparece como um instrumento teórico-metodológico em que a relação entre os elementos que compõem um sistema é analisada com uma visão de totalidade.

O termo geossistema é usado para expressar a conexão entre natureza e sociedade. "Os geossistemas são considerados fenômenos naturais, mas na sua análise leva em consideração aspectos sociais e econômicos (...) são sistemas dinâmicos e com estágios de evolução temporal, sob a influência do homem" (GUERRA e GUERRA, 2005, p. 322).

No Brasil, a tradução e o uso dos artigos de George Bertrand (1972) trouxeram importante contribuição para as pesquisas, por empregar o conceito de geossistema como base para os estudos de organização do espaço, dado sua compatibilidade com a escala humana. Para o autor, o geossistema corresponde a dados ecológicos relativamente estáveis, resultantes da combinação de fatores geomorfológicos (natureza das rochas e dos mantos superficiais, valor do declive, dinâmica das vertentes), climáticos (precipitação, tem- peratura) e hidrológicos (lençóis freáticos epidérmicos e nascentes, $\mathrm{pH}$ das águas, tempos de ressecamento do solo).

A compartimentação espacial através da visão geossistêmica, conforme Freitas e Cunha (2004), estabelece critérios que buscam a identificação e o agrupamento do comportamento das variáveis ambientais, destacando os processos morfodinâmicos da paisagem de origem natural (geologia, geomorfologia, clima, hidrologia e ecossistemas) e antrópica (baseada na ocupação sócio-histórica).

A cartografia geoambiental surge como forma de avaliar as potencialidades dos recursos naturais. Conforme Amaral e Ross (2004), consiste em relacionar os dados de geologia, geomorfologia, pedologia, clima, vegetação e de uso da terra. Assim, a avaliação integrada e sistêmica desses fatores permite a análise da fragilidade dos ambientes e a elaboração de possíveis propostas para seu uso sustentável.

O zoneamento geoambiental pode ser caracterizado como um instrumento de auxílio no planejamento e no ordenamento territorial, em escala regional ou local. Desta forma, os estudos de natureza geoambiental possibilitam a caracterização de áreas quanto as suas aptidões e restrições às atividades já em desenvolvimento e/ou prováveis de serem implantadas, além de indicar porções do terreno com uma maior qualidade ambiental que possam ser preservadas (GRECCHI, 1998).

O desafio de pesquisar elementos e de adequar uma metodologia para o diagnóstico e o zoneamento geoambiental da situação real da paisagem escolhida mostra-se oportuno e estimulante, dada sua dinâmica passada e recente. $\mathrm{O}$ ambiente de colinas conhecidas regionalmente por "coxilhas" 1 com vegetação de campos, habitat da figura típica do Rio Grande do Sul, o gaúcho, tem sofrido, especialmente na década de 1970 , com a agricultura mecanizada e, atualmente, com atividade da silvicultura, ocasionando mudanças que criam novos cenários com usos diversificados. Além disso, nessa região do Estado, são significativos processos de erosão acelerados por areais e voçorocas.

\footnotetext{
1 Termo de origem espanhola que representa uma denominação regional das elevações alongadas de pouca altitude, com topos arredondados, cujo perfil, visto de longe, apresenta um aspecto de faca ('cuchilla'), que se destacam na região dos campos sul-brasileiros e uruguaios.
} 
Neste contexto, o entendimento da gênese natural/antrópica da fragilidade das paisagens e da ocupação dos espaços, por vezes de forma inadequada e causando graves consequências ao ambiente, impõe a necessidade do Zoneamento Ambiental a fim de compatibilizar e adequar os usos e a ocupação da terra.

Sob este enfoque foram escolhidas as bacias hidrográficas contíguas que ficam entre os municípios de Manoel Viana e São Francisco de Assis, na região oeste do Estado do Rio Grande do Sul. A área abrange cerca de $1.500 \mathrm{~km}^{2}$, entre as coordenadas geográficas de longitude $55^{\circ} 49^{\prime} 55^{\prime \prime}$ e $55^{\circ} 00^{\prime} 38^{\prime \prime}$ oeste e latitude $29^{\circ} 18^{\prime} 36^{\prime \prime}$ e 29 $37^{\circ} 16^{\prime \prime}$ sul. A área compreende os limites físicos das bacias hidrográficas existentes entre os municípios de São Francisco de Assis e Manoel Viana. As bacias hidrográficas são delimitadas de leste para oeste pelo Arroio Miracatu, Arroio Caraguataí, Restinga do Salso, Arroio Piraju e Lajeado Cunha (Figura 1).

A proposta de Zoneamento Geoambiental deste trabalho está fundamentada numa análise integrada dos componentes antrópicos e naturais da paisagem considerada, mediante a caracterização dos elementos básicos que a formam. Através da cartografia analítica e da interpretação analítico-integrativa, são produzidos documentos-síntese (documentos finais) que concretizam o zoneamento.

\section{METODOLOGIA}

A metodologia de zoneamento geoambiental tem como premissa a compartimentação da paisagem com base nas características geoambientais, em suas inter-relações e relações com as atividades antrópicas, colocando em evidência suas potencialidades e restrições de uso.

Para o zoneamento geoambiental foram utilizadas as concepções da cartografia geoambiental adotada por Zuquette (1987), o qual afirma ser um processo que tem por finalidade básica levantar, avaliar e analisar os atributos que compõem o meio físico, quer sejam geológicos, hidrológicos e outros.

Além disso, seguiu-se a indicação de Cendrero (2004), o qual propõe a escala 1:50.000 como adequada para a elaboração dos mapeamentos temáticos,

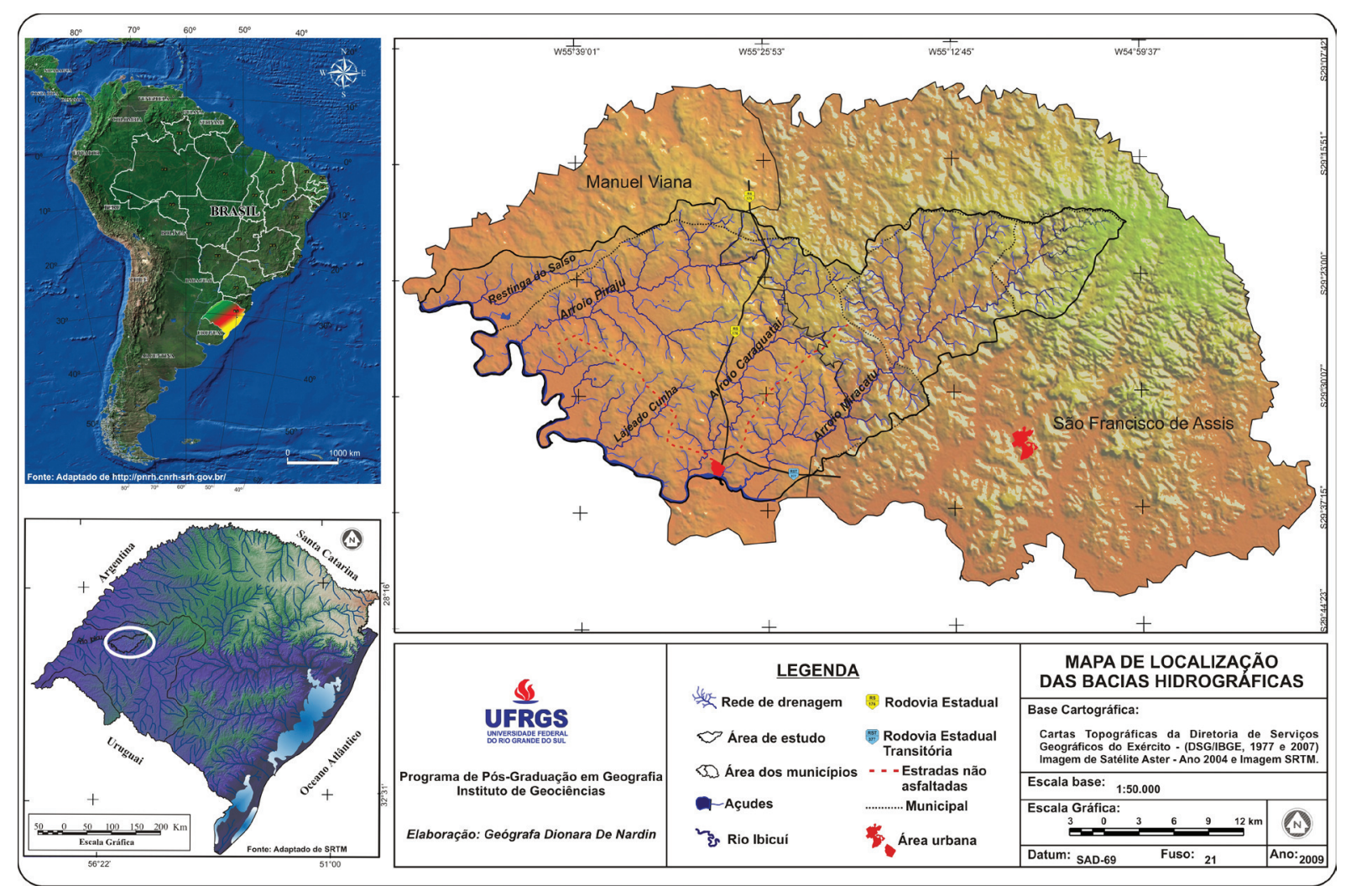

Figura 1: Localização da área de estudo 
por oferecer o nível de detalhe eficiente para estudos dessa natureza - o Zoneamento Geoambiental - sendo uma etapa intermediária para as propostas que tenham como premissa o planejamento e a gestão ambiental.

A construção de um banco de dados georreferenciado no software SPRING (Sistema de Processamento de Informações Georreferenciadas) em associação com o ArcGIS, contendo todas as informações dos levantamentos, contribuiu para a organização e manipulação dos dados, além de permitir maior percepção das inter-relações e sistematizações entre os elementos constituintes da paisagem. O tratamento e a classificação das imagens de satélite foram elaborados no software Envi, junto ao Centro Estadual de Pesquisas em Sensoriamento Remoto e Meteorologia (CEPSRM) da Universidade Federal do Rio Grande do Sul.

O levantamento cartográfico serviu de apoio para a construção dos mapas. A base cartográfica utilizada foram as cartas topográficas elaboradas pela Diretoria de Serviços Geográfico (DSG/IBGE, 1977, 2007) do Ministério do Exército, na escala 1:50.000, que após serem atualizadas, permitiram a definição do mapa base da área de estudo. Aárea de estudo abrange sete cartas topográficas definidas pela seguinte denominação e nomenclatura: Caraguataí (SH. 21-XD-I-3), Vila Kramer (SH. 21-XD- I-4), Manoel Viana (SH. 21-X-D-IV-1), São Francisco de Assis (SH. 21-X-DIV-2); Chalé (SH. 21-X-C-III-3), Arroio Piraju (SH. 21-X-CIII-4), Passo Novo (SH. 21-X-CVI- 2).
O mapa base representa as informações da fisionomia dos diferentes elementos e das formas que configuram a topografia. Esses elementos compreendem as curvas de nível, os pontos cotados e a rede de drenagem. A rede de drenagem sofreu atualizações através das imagens de satélite recentes, e das informações de campo.

As imagens de satélite dos sensores Landsat 5 TM e 7 ETM+, CBERS 2B, Aster, Ikonos, os modelos digitais de elevação do SRTM, e fotografias aéreas de baixa altitude integraram o material cartográfico disponível para a execução da pesquisa.

Estudos específicos de mapeamento que abrangem a área pesquisada, como o Projeto RADAMBRASIL/IBGE $(1973,2003)$, o mapeamento de solos realizado por Streck et al. $(2002,2008)$, além dos estudos mais aprofundados de Verdum (1997), do Atlas de Arenização desenvolvido por Suertegaray et al. (2001) e do mapeamento geoambiental da Bacia Hidrográfica do Itu, apresentado por Trentin (2007), também auxiliaram no desenvolvimento do trabalho.

Todas as informações levantadas, processadas, analisadas, correlacionadas e por fim mapeadas serviram de base para a caracterização geoambiental. As categorias de informação analisadas e levantadas são as classes de documentos Básicos, Derivados, Interpretativos e Finais, que em termos cartográficos representam a cartografia analítica e de síntese, que podem ser visualizados na Figura 2.

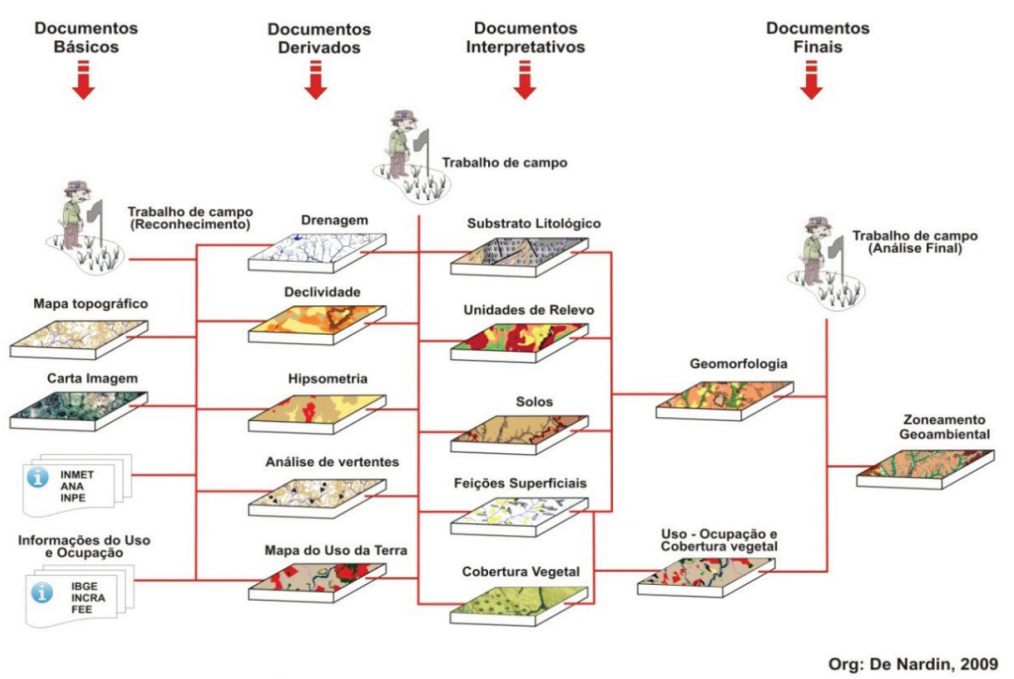

Figura 2: Esquema dos documentos levantados e desenvolvidos para o Zoneamento. Organização: De Nardin (2009). 


\section{RESULTADOS}

O zoneamento geoambiental da área de estudo representa a síntese de todos os levantamentos realizados, além de indicar o comportamento da paisagem frente aos processos superficiais e antrópicos. De modo geral, as zonas identificadas são caracterizadas por aspectos como: rede de drenagem, litologias, vegetação e espécies endêmicas, solos e feições superficiais, e principais tipos de uso.

Optou-se pela descrição e pelo entendimento dos processos que deram origem ao zoneamento, através da separação de sistemas e unidades. O uso de dois níveis hierárquicos foi adotado em virtude de se buscar o significado de cada zona geoambiental (sistemas e unidades), em se tratando de alterações na paisagem desencadeadas por processos naturais e antrópicos. antrópicas desenvolvidas. Motivo pelo qual serão descritos separadamente.

Sistema: Maior nível hierárquico que representa a associação de condições similares de processos e características ambientais, manifestadas por um mínimo de uniformidade de substrato, solos, geomorfologia, entre outros.

Unidade: Subdivisão de Sistema, a qual se distingue por apresentar determinados processos e características que refletem em nível de diferenças e uniformidade, em termos de usos da terra, processos de erosão e vegetação atípica dos demais sistemas, entre outros.

As características ambientais definidas permitiram a identificação de seis Sistemas e nove Unidades definidos por um ou mais atributos da paisagem (Figura 3).

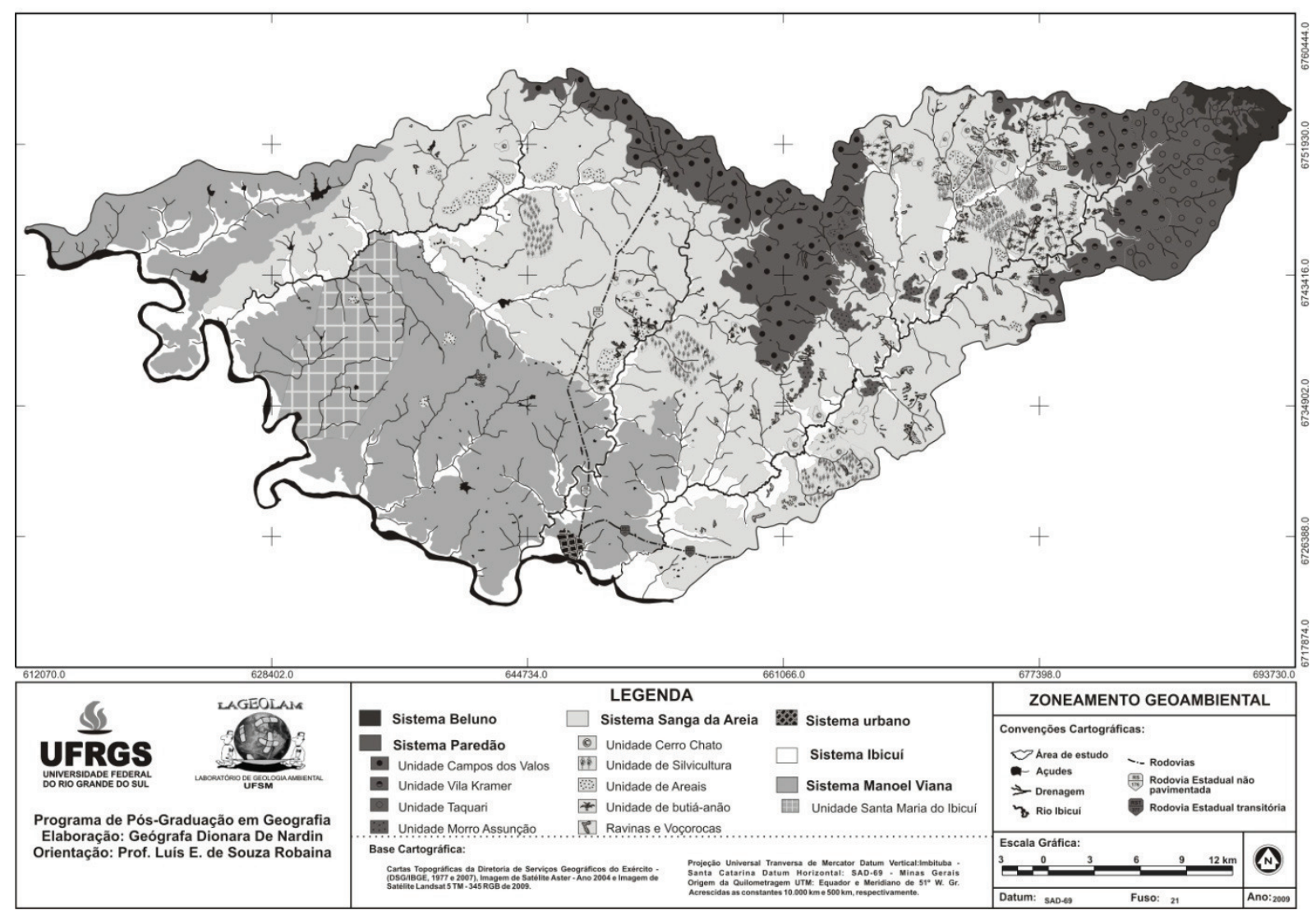

Figura 3: Zoneamento Geoambiental da área de estudo.

Além disso, os níveis hierárquicos adotados apresentam, como se terá oportunidade de verificar, algumas diferenças nas técnicas e nos critérios de análise, as quais incluem diferenças nas atividades

\section{Sistema Urbano}

O sistema urbano representa a área urbana da cidade de Manoel Viana, que é formada por seis bair- 
ros identificados no mapa (Figura 4) como Bairro Vila Nova, Centro, Cidade Baixa, Progresso, Navegantes e Restinga. Com uma área atual de 220,3 ha (IBGE, 2009) e localizada nas margens do Rio Ibicuí, a cidade de Manoel Viana - RS está assentada sobre substrato de rocha vulcânica, solos argilosos e rasos e solos hidromórficos nas proximidades do Ibicuí.

As características das ocupações são homogêneas, com construções baixas e o predomínio de áreas residenciais, mesmo na zona central. Por sua emancipação recente, apresenta limitações de infraestrutura e saneamento básico, tendo como principal conflito ambiental a contaminação das águas do Rio Ibicuí devido o lançamento de esgotos.

\section{Sistema Ibicuí}

Neste sistema ocorrem os depósitos recentes, localizados próximos ao canal principal dos arroios e aos seus afluentes, que possibilitam o desenvolvimento, nestas várzeas, de solos mal drenados, identificados como hidromórficos.

A faixa próxima à área de acumulação do Rio Ibicuí (Figura 5) também pertence a este sistema, onde se desenvolvem os planossolos, que são solos mal drenados e ocorrem associados a substratos de arenitos e rochas vulcânicas. Também ocorrem associados às áreas de deposição, solos novos muito quartzosos, denominados Neossolos Quartzarênicos.

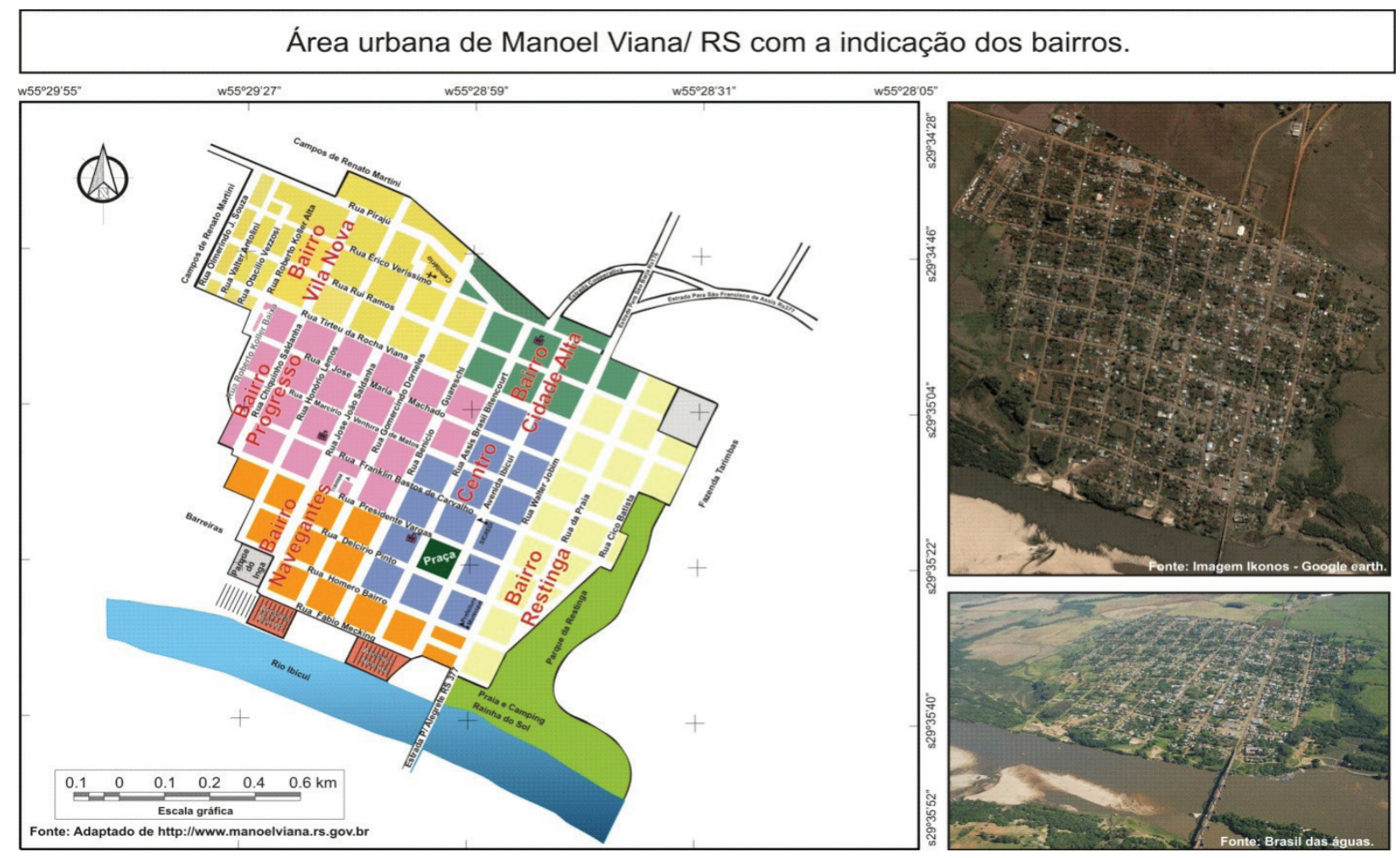

Figura 4: Ilustração da área urbana de Manoel Viana com localização dos bairros.

Organização: De Nardin (2009)

Outros impactos do sistema urbano nas características naturais e na fisiologia da paisagem são visíveis como, por exemplo, as alterações na drenagem a leste da cidade, onde avançam as construções; a impermeabilização nas margens do Ibicuí; a construção de aterros para os terrenos; a geração de resíduos sólidos sem uma adequada área de descarte e a instauração das vias de acesso.
Ao longo dos canais principais e do Rio Ibicuí se desenvolve uma mata ciliar em forma de faixas, cujas espécies mais características são o sarandi (Sebastiania schottiana), o coqueiro-gerivá (Syagrus romanzoffiana), o branquilho (Sebastiana commersoniana), a pitangueira (Eugenia uniflora), o camboatá-branco (Matayba elaeagnoides) e a aroeira-cinzenta (Schinus lentiscifolius). 
Com relação ao relevo, estas áreas são definidas como rampas e apresentam declividades menores que $5 \%$, caracterizadas por uma topografia plana e altitudes podendo atingir 200 metros no alto curso dos arroios.

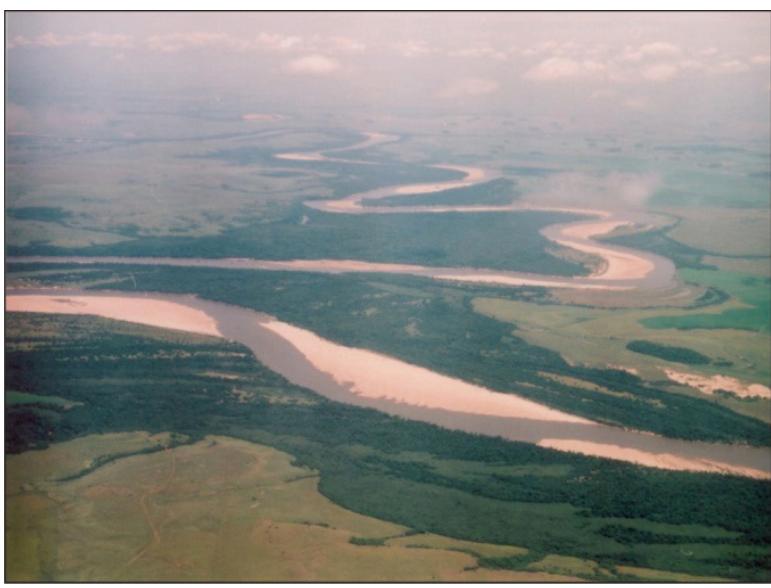

de colinas arenosas côncavo-convexas predominam os solos espessos, profundos, arenosos e friáveis, com pouco material ligante, desenvolvidos sobre substrato de arenitos, sendo classificados como latossolos arenosos e, até mesmo, neossolos, em declividades variadas

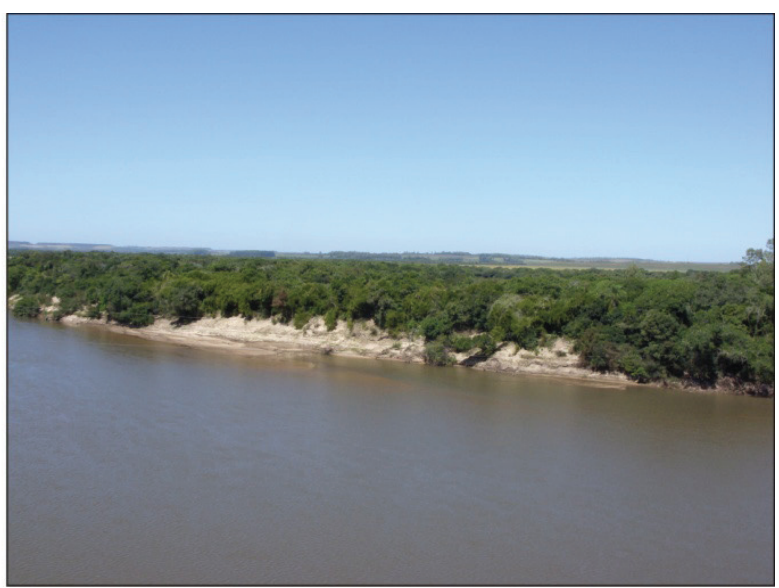

Figura 5: Fotografias das áreas de acumulação do Sistema Ibicuí.

Fonte: Trabalho de campo.

A principal atividade desenvolvida é o cultivo de arroz, que se associa à disponibilidade hídrica e à potencialidade do solo. Grandes áreas alagadas, onde antes havia banhados, foram drenadas para o plantio de arroz.

A maior fragilidade deste sistema está associada aos banhados ${ }^{2}$ e à mata ciliar, que vem sendo retirada nas últimas décadas, dando lugar para o desenvolvimento da agricultura. A vegetação arbórea mantém-se, dentro das áreas de proteção exigidas pela legislação ambiental, apenas em algumas faixas no canal principal dos arroios ${ }^{3} \mathrm{e}$, em algumas áreas, ao longo do Rio Ibicuí.

\section{Sistema Sanga da Areia}

Este sistema apresenta as áreas de maior fragilidade, onde predominam litologias friáveis identificadas como arenitos da Formação Guará, que pela fácil desagregação condicionam a formação de feições erosivas de grandes extensões (Figura 6). No relevo

\footnotetext{
${ }^{2}$ Termo derivado do espanhol bañado e usado principalmente no sul do Brasil para as extensões de terras baixas e inundadas pelos rios, que podem, periodicamente, apresentarem-se secos (GUERRA e GUERRA, 2005).

${ }^{3}$ Denominação atribuída aos pequenos rios do sul do Brasil.
}

em que predominam inclinações de 5 a $15 \%$. A baixa densidade de drenagem que ocorre na Sanga da Areia associa-se às características de permeabilidade das rochas e dos solos. Uma importante feição superficial presente neste sistema são as voçorocas nas cabeceiras de drenagem.

As elevadas precipitações médias anuais de 1739 mm vão comprometer os sistemas geoambientais mais fragilizados, como o Sistema Sanga da Areia. Além da chuva, considera-se também que os ventos têm uma atuação importante em porções onde o solo e a rocha apresentam-se desagregados, gerando depósitos arenosos.

Quanto ao uso, predominam os campos com atividade pecuária. Entretanto, com vastas áreas sendo utilizadas para a agricultura e atualmente, a silvicultura.

Com relação à vegetação, esse sistema é composto por formações campestres, capões de mato, eucaliptos e mata ciliar, bastante degradada, ao longo dos arroios, além do butiá-anão nas colinas arenosas.

A diversidade presente neste sistema permitiu a distribuição de quatro unidades com características semelhantes: 


\section{Unidade Cerro Chato}

Esta unidade contempla os morrotes e as cornijas ${ }^{4}$ de arenito, que ocorrem associados às áreas de litologias fluviais de alta coesão com afloramento de rochas. Os morrotes representam uma topografia típica da região, com topos planos e encostas íngremes com vertentes retilíneas e vegetação mais abundante nas escarpas.

As declividades nas encostas dos morrotes são superiores a $15 \%$, e os topos são planos. O morrote de maior altitude possui 277 metros e ocorre nas proximidades da Sanga da Areia.

Nesta unidade os solos são rasos ou não ocorrem e os processos erosivos são identificados, com muita frequência, na base dos morrotes de arenito, nas zonas de contato com o relevo de colinas. Uma vez desencadeados, tais processos têm como consequência a formação de ravinas, voçorocas e areais.

A condição climática atual da região auxilia na decomposição e desagregação das camadas resistentes dos morrotes, que favorecem a formação das manchas arenosas. Os intensos processos de voçorocamento que ocorrem junto à base dos morrotes carregam grande quantidade de areia para as drenagens.

A vegetação característica dos morrotes de arenito contempla diversas espécies, com destaque para a criúva (Agarista eucalyptoides), o jasmimcatavento (Tabernaemontana catharinensis), o curupi (Sapium haematospermum) e a tuna (Cereus hildmannianus). No topo, a vegetação rasteira adaptou-se às condições locais de baixa umidade e solos rasos, e mesmo com as dificuldades de acesso, encontra-se pouco preservada devido ao uso agropecuário. Em alguns casos, como no Cerro Chato que dá nome a esta unidade (Figura 6 a), as atividades agrícolas já alcançaram a área de topo em décadas anteriores e atualmente são visíveis os campos com solos exposto.

Em outros casos, os topos dos morrotes de arenito e cornijas estão sendo ocupados com atividades de silvicultura.

As cornijas compreendem os degraus de rochas areníticas que formam saliências na topografia,

4 Do italiano Corniche, que significa coroa. A cornija é um termo regional que representa uma forma de relevo abrupta saliente, de dimensões variadas, capeada por uma camada de rocha dura (GUERRA e GUERRA, 2005). semelhante aos morrotes, porém se diferenciam por apresentarem amplitudes menores e formarem faixas, não sendo individualizadas como os morrotes isolados.

A vegetação das cornijas costuma se desenvolver com maior abundância na encosta menos ensolarada e com maior quantidade de umidade, sendo comum a presença da criúva (Agarista eucalyptoides) associada ao jasmim-catavento (Tabernaemontana catharinensis), além de muitas cactáceas. Em alguns casos, quando as cornijas estão próximas à rede de drenagem, aparecem espécies como o coqueiro-gerivá (Syagrus romanzoffiana).

Os usos limitam-se à retirada da vegetação das cornijas. Já no limite com as colinas, onde a quantidade de rocha diminui, permite-se que o uso possa ser desenvolvido com lavouras e atividade de pecuária.

\section{Unidade Silvicultura}

A unidade de silvicultura compreende as plantações de pinus e eucaliptos e foi separada por representar uma proposta de novos usos para dinamizar a metade sul do Estado, que inclui a área de estudo. Além disso, é importante ressaltar que a presença da vegetação exótica faz com que a ação dos agentes de erosão, vento e água, seja modificada e, portanto, altera a dinâmica superficial da região, ainda pouco estudada (Figura 6 b).

A silvicultura é recente, na área de estudo, e as plantações comerciais ocorrem em 2.740 ha da área total, em locais que anteriormente se desenvolviam campos com pecuária e agricultura, além de porções com processos de arenização.

As extensas áreas para essa atividade incorporam zonas de arenização, o que se apresenta como ponto positivo para os moradores da região. Entretanto, em termos ecológicos, as plantações estão sendo destruídas em áreas que marcam uma condição paleoclimática regional e que determinam o bioma Pampa, no sul do Brasil.

\section{Unidade Areais}

A individualização desta unidade deve-se à grande extensão e à representatividade que o processo de arenização tem na área de estudo. Os areais ocorrem 

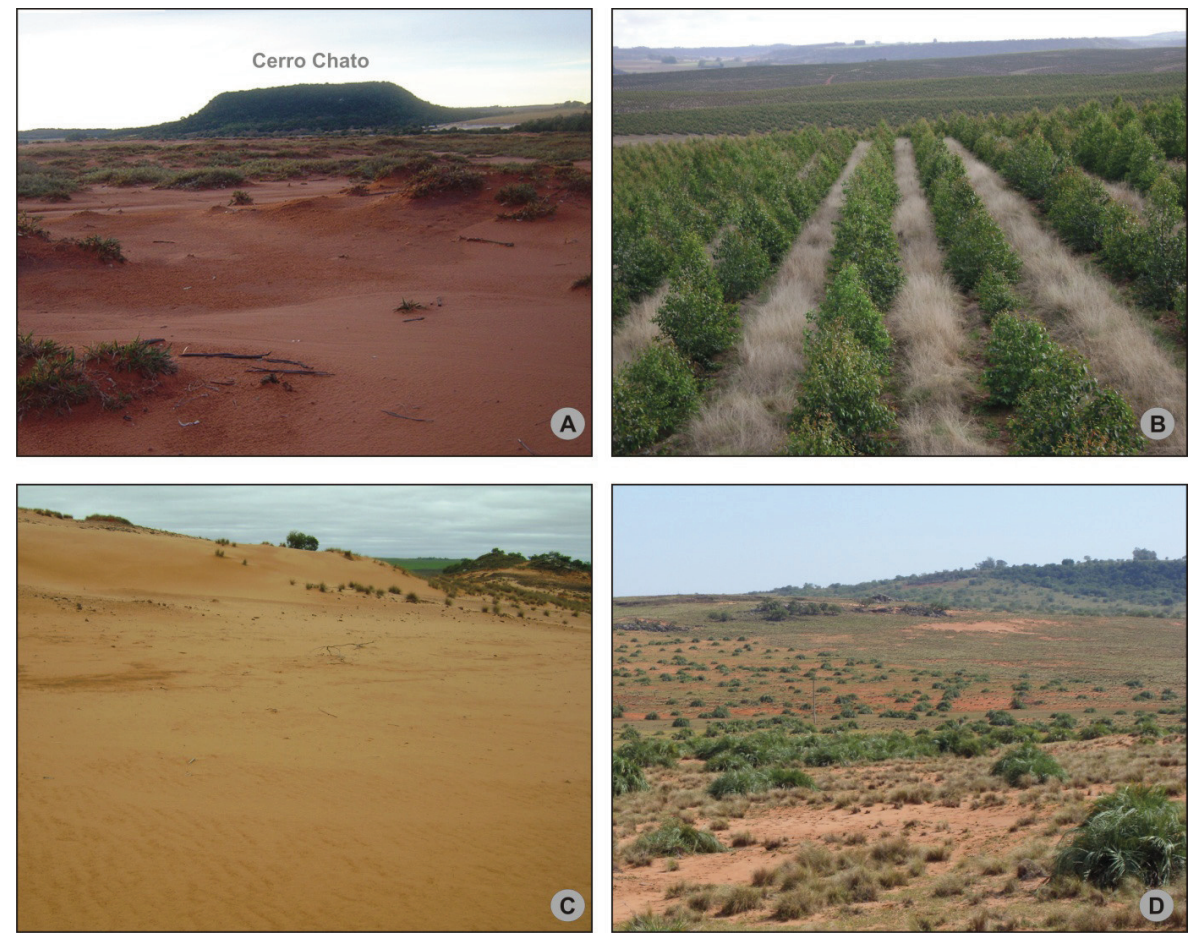

Figura 6: Fotografias registrando o Sistema Sanga da Areia. (a) Unidade Cerro Chato identificada por morrotes de arenito. (b) Plantação de eucalipto formando a Unidade Silvicultura. (c) Areais de grande extensão formando a Unidade Areais. (d) Butiazeiros anões cobrindo as colinas arenosas.

Fonte: Trabalho de campo.

em cerca de 1.700 ha da área, tendo intensa dependência com as características litológicas (Figura $6 \mathrm{c}$ ).

Ressalta-se que, quanto à gênese, a maioria dos areais da área de estudo se forma em condições específicas, em que os processos erosivos desagregam e depositam a areia proveniente das rochas areníticas, formando os depósitos arenosos não consolidados.

A evolução do processo de arenização associase com a dinâmica dos ventos predominantes na região, com direção sudeste no inverno e de nordeste na primavera, que juntamente com a erosão hídrica, espalham as areias, ampliando os processos de arenização. É indiscutível também que o uso intensivo dos solos fragilizados da área contribua para a evolução dos processos erosivos.

As feições erosivas do tipo ravina e voçoroca ocorrem de forma mais intensa nas porções com arenitos fluviais. Por serem feições bem características de sistemas fragilizados, as ravinas e voçorocas foram individualizadas em toda a área, aparecendo de forma mais expressiva no Sistema Sanga da Areia.

\section{Unidade das colinas com butiá-anão}

As colinas com butiá-anão foram definidas como unidade por sua representação ecológica, marcando um importante aspecto do Bioma Pampa. Por sua ocorrência restrita no oeste e sudoeste do Estado, o butiá-anão (Butia lallemantii) representa importante espécie endêmica que caracteriza o Bioma Pampa e atribui um aspecto de savana à vegetação campestre local.

Ocorrem exclusivamente associadas a substrato de arenitos fluviais, identificados no Sistema Sanga da Areia, em declividades variadas. Sendo que na porção identificada nas proximidades do Arroio Piraju, as declividades são inferiores a $2 \%$. Todos os campos com butiá-anão foram encontrados em altitudes na classe entre 120 e 200 metros.

A unidade com butiá-anão aparece de forma expressiva na área de estudo em uma extensão total de 903,41 ha. Nota-se, entretanto, que a ocorrência de alguns polígonos com butiá não se encontra conectada, e sua interrupção está associada ao desenvolvimento 
de lavouras (Figura $6 \mathrm{~d}$ ).

Como os limites dessa unidade coincidem com as lavouras, infere-se que os campos com butiás eram bem mais expressivos em períodos anteriores ao desenvolvimento agrícola na área de estudo. Além disso, a atividade de silvicultura vem sendo incorporada nas áreas com butiás. As características apresentadas mostram a importância dessa espécie que, por ser típica do ecossistema do Bioma Pampa e estar perdendo espaço pela agricultura e silvicultura, deve ser preservada, para que nos próximos anos não venha a ser extinta do seu ambiente original, o pampa gaúcho.

\section{Sistema Manoel Viana}

O Sistema Manoel Viana compreende as colinas que ocorrem em litologias vulcânicas de pouca espessura e que apresentam, em sua maioria, solos profundos e bem desenvolvidos, relativamente mais coesos pela presença de frações argilosas.

Por serem pouco espessos, os derrames presentes nesta unidade permitem a exposição de pequenas manchas arenosas.

O sistema de canais que drena estas zonas é formado por nascentes e canais de até $4^{\mathrm{a}}$ ordem. $\mathrm{O}$ relevo deste sistema é formado por colinas em áreas de baixa altitude e com declividades variadas, predominando faixas inferiores a $5 \%$, mas chega a apresentar pequenas faixas com inclinações maiores de $15 \%$. Isso possibilita pequenas variações dos tipos de solos, de acordo com as inclinações do terreno, mas o que predomina são solos bem desenvolvidos, como Argissolos e os Latossolos. As feições erosivas presentes nesta unidade estão relacionadas à exposição dos arenitos.

De modo geral, a vegetação arbórea deste sistema se distribui ao longo dos canais, na forma de capões de mata próximos às nascentes e de alguns pequenos bosques de eucalipto.

O tipo de uso realizado nesta unidade é a associação pecuária e agricultura, sendo esta última desenvolvida muito próxima as drenagens, favorecendo a degradação das margens dos canais com a retirada da vegetação, conforme mostra a Figura 7 (a). Por apresentar uma porção com características diferenciadas, foi delimitada a unidade Santa Maria do Ibicuí, com usos e tamanho das propriedades distintos daqueles apresentados como característica geral.

\section{Unidade Santa Maria do Ibicuí}

Esta unidade foi individualizada por apresentar uma distribuição fundiária e de usos diferenciados do restante do sistema Manoel Viana. Estes locais são formados por minifúndios que compõem o Assentamento Santa Maria do Ibicuí, onde há usos diversificados da terra nas áreas de colinas (pecuária leiteira, lavouras de milho, feijão, batata, entre outros) formadas por solos arenosos e nas várzeas ocorre o cultivo de arroz em solos hidromórficos (Figura 7 b).
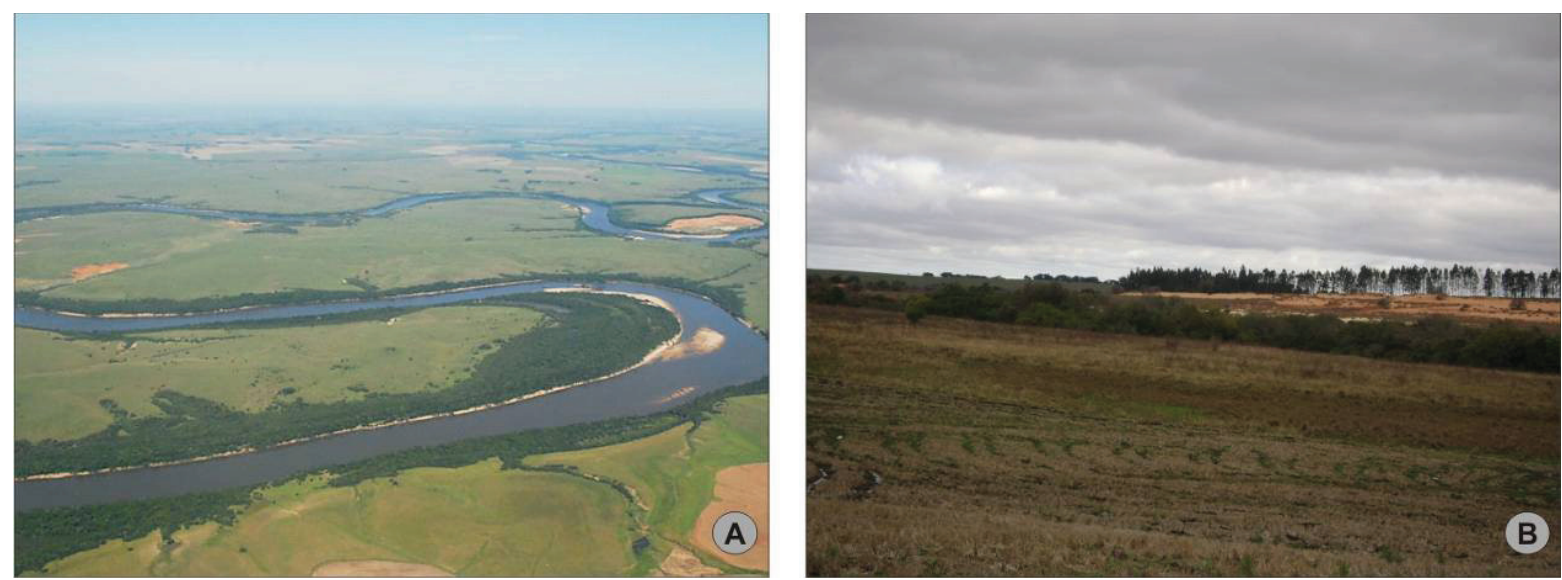

Figura 7: Fotografias do Sistema Manoel Viana. (a) Fotografia demonstrando o avanço da agricultura próximo ao Rio Ibicuí. (b)

Fotografia retirada no Assentamento Santa Maria do Ibicuí, onde é desenvolvido o plantio de arroz, junto às várzeas.

Fonte: Trabalho de campo. 
A unidade é formada, em sua maioria, pelas planícies de inundação do Ibicuí e do Piraju, compondo uma topografia com declividades inferiores a $2 \%$. Por esse motivo, apresenta uma importante contribuição das drenagens dos afluentes do Piraju e dos canais que deságuam junto ao Ibicuí.

As porções de maior declividade se reduzem às áreas de colinas com encostas mais íngremes, onde predominam declividades de 5 a 15\%. As altitudes não ultrapassam os 160 metros, predominando altitudes inferiores a 100 metros.

As litologias são predominantemente arenosas, formadas por arenitos fluviais e eólicos. Manchas arenosas e ravinas foram observadas no interior desta unidade, confirmando a fragilidade da paisagem.

A cobertura vegetal desta unidade é predominantemente campestre, tendo as maiores fragilidades associada à escassa vegetação ciliar, estando restrita a alguns capões nas cabeceiras de drenagens.

\section{Sistema Paredão}

Este sistema é assim chamado por sua toponímia indicada no alto curso do Arroio Caraguataí e Piraju, onde é visível a formação de verdadeiros paredões vegetados com declividades superiores a 15\%.

Os processos de dissecação permitiram a distribuição de quatro unidades com características distintas (Figura 8).

\section{Unidade Campos dos Valos}

A unidade Campos dos Valos compreende as colinas, em associação com morrotes e escarpas abruptas, que ocorrem em litologias de rochas vulcânicas com algumas porções de arenito Botucatu intertrápico aflorante.

As altitudes chegam a atingir 300 metros e representam as áreas dissecadas do rebordo, onde a menor quantidade de derrames demonstra a influencia dos processos erosivos que possibilitaram o aparecimento de finas camadas de arenitos. A vegetação destes paredões é composta por diversas espécies (Figura 8 a) entre as mais comuns estão à canela-deveado (Helietta apiculata), a timbaúva (Enterolobium contortisiliquum), a pitangueira (Eugenia uniflora), o ipê-roxo (Tabebuia impetiginosa), a primavera (Brunfelsia pauciflora) e o gravatá (Bromelia balansae).

Nas áreas localizadas acima dos paredões, predominam os campos com pecuária. Os solos desenvolvidos são rasos, definidos como Neossolos Litólicos. No topo podem ocorrer solos mal desenvolvidos, classificados pela associação de Argissolos/ Cambissolos.

\section{Unidade Morro Assunção}

Esta unidade corresponde aos morros testemunhos de rochas vulcânicas, que ocorrem de forma mais expressiva na margem direita do Arroio Miracatu e apresentam expressiva vegetação nativa. As escarpas desses morros são íngremes, com inclinações superiores a 15\%. A maior altitude desta unidade é $209 \mathrm{~m}$ e ocorre no Morro Assunção.

Os solos distribuem-se em Neossolos e Cambissolos. Os morrotes apresentam vegetação arbórea abundante (Figura 8 b), a maioria dentro dos limites estabelecidos para áreas de proteção. Algumas espécies são bem características desses morrotes, como a aroeira-brava (Lithraea molleoides), a canela-deveado (Helietta apiculata), o angico-vermelho ( $\mathrm{Pa}$ rapiptadenia rigida).

\section{Unidade Taquari}

Esta unidade representa as áreas de transição entre a Depressão e o Planalto, sendo formada por morros e morrotes associados a um relevo escarpado em altitudes elevadas. As litologias são de arenitos Botucatu e rochas vulcânicas. As declividades variam de 5 a 15\% e superiores a 15\%, manifestando processos de dinâmica superficial como erosão, rolamento e queda de blocos.

Seu uso é restrito devido ao relevo, ocorrendo somente pequenas áreas com atividade agrícola e pecuária, onde a distribuição fundiária é com pequenas propriedades. Nestas áreas de relevo movimentado, associado a morros e morrotes, ocorrem solos rasos no topo, constituindo cambissolos e, na encosta, afloramentos de rocha e neossolos litólicos. Uma característica bem marcante dessa unidade é a extensa área de vegetação arbórea, acompanhando toda a sequência da escarpa e as drenagens (Figura $8 \mathrm{c}$ ). 
Entre as espécies mais comuns da Unidade Taquari encontram-se a aroeira-brava (Lithraea molleoides), o pau-ferro (Astronium balansae), a pitangueira (Eugenia uniflora), a timbaúva (Enterolobium contortisiliquum), a canela-de-veado (Helietta apiculata), o araticum (Rollinia emarginata) e o espinilho (Acacia caven).

Esta porção da área de estudo apresenta uma vegetação bem diversificada, mas o que vem ocorrendo é a devastação em zonas no interior da mata fechada.

\section{Unidade Vila Kramer}

A unidade Vila Kramer representa a zona de transição entre o Sistema Sanga da Areia e a Unidade Taquari, em uma porção bem individualizada por escarpas (Figura $8 \mathrm{~d}$ ).
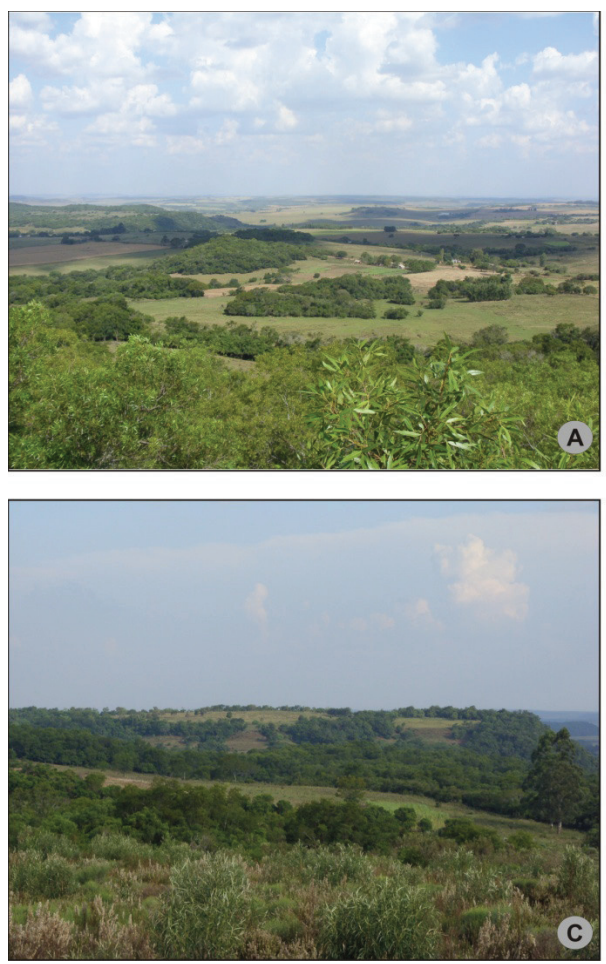

Figura 8: Fotografias do Sistema Paredão. (a) Morrotes vegetados da Unidade Campos dos Valos. (b) Unidade vegetada do Morro Assunção. (c) Vegetação arbórea acompanhando a escarpa da Unidade Taquari. (d) Unidade Vila Kramer, formada por amplos patamares. Fonte: Trabalho de campo.

Nesta unidade ocorre o contato entre as litologias vulcânicas e os arenitos eólicos e fluviais, em um relevo formado por patamares amplos e declividades mais suaves.

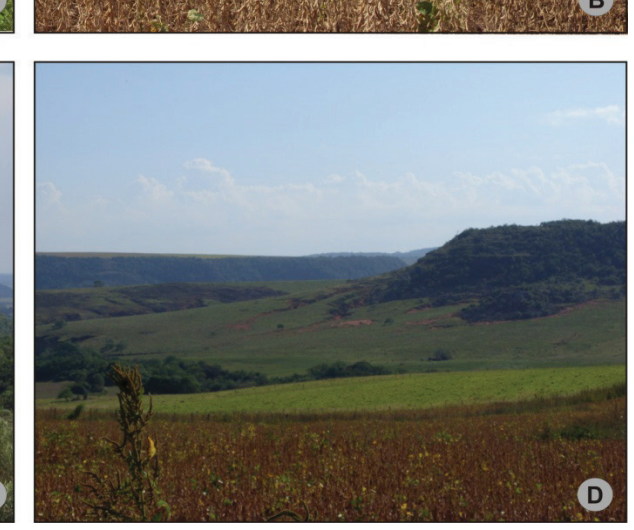

Está localizada na porção sul da Vila Kramer, onde se encontram pequenas propriedades próximas à vila e no Distrito Sede, com usos diversificados. No centro desta unidade ocorrem lavouras em propriedades de maior extensão.

\section{Sistema Beluno}

O sistema descrito pertence ao distrito Beluno, onde residem pequenas propriedades, em cujos limites da área de estudo, por serem divisores com topos mais planos e solos rasos, se desenvolve a pecuária leiteira (Figura 9).

Este sistema é caracterizado por apresentar uma extensa cobertura de campos, formando um denso tapete gramíneo herbáceo, de espécies conhecidas, como o capim-caninha (Andropogon lateralis) e a grama-forquilha (Paspalum notatum). São locais de

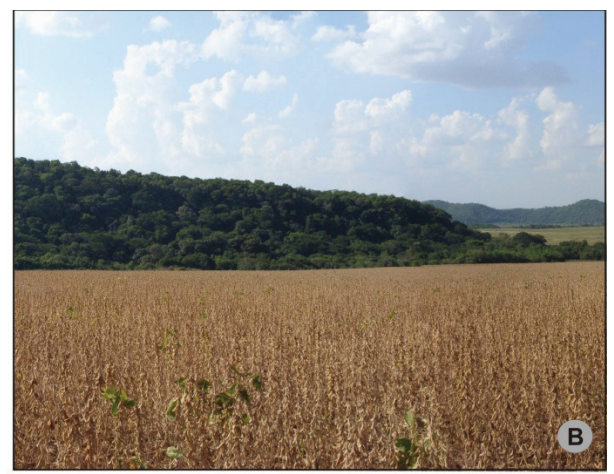

forte contribuição de nascentes que se desenvolvem sobre espessas camadas de rochas vulcânicas, que ocorrem nas maiores altitudes da área, acima de 400 metros. 

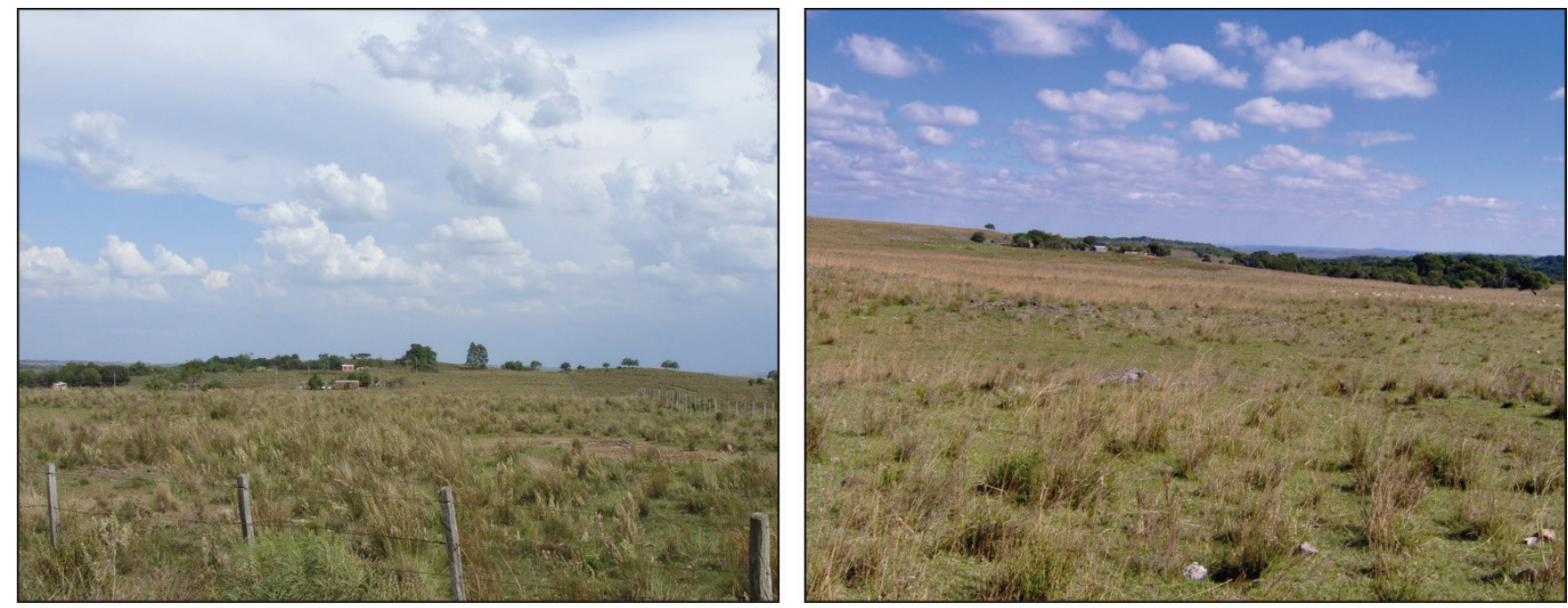

Figura 9: Fotografias registrando as pequenas propriedades do Sistema Beluno.

Fonte: Trabalho de campo.

Além disso, apresentam um substrato identificado como de composição vulcânica de termos mais ácidos (WILDNER et al., 2006), apresentando forte disjunção tabular no topo e maciço na porção central dos derrames. Esta pequena faixa, localizada na área de estudo, avança em direção ao município de Santiago. É comum a exposição destes derrames na forma de rochas expostas nos campos, compondo solos de pouca profundidade e pedregosos.
O esquema apresentado a seguir (Figura 10) proporciona uma visão conjunta de todos os sistemas identificados na proposta de zoneamento, bem como ilustra as principais características diferenciadas em cada unidade de análise.

\section{CONCLUSÕES}

O presente trabalho objetivou analisar os elementos do meio físico e os processos superficiais

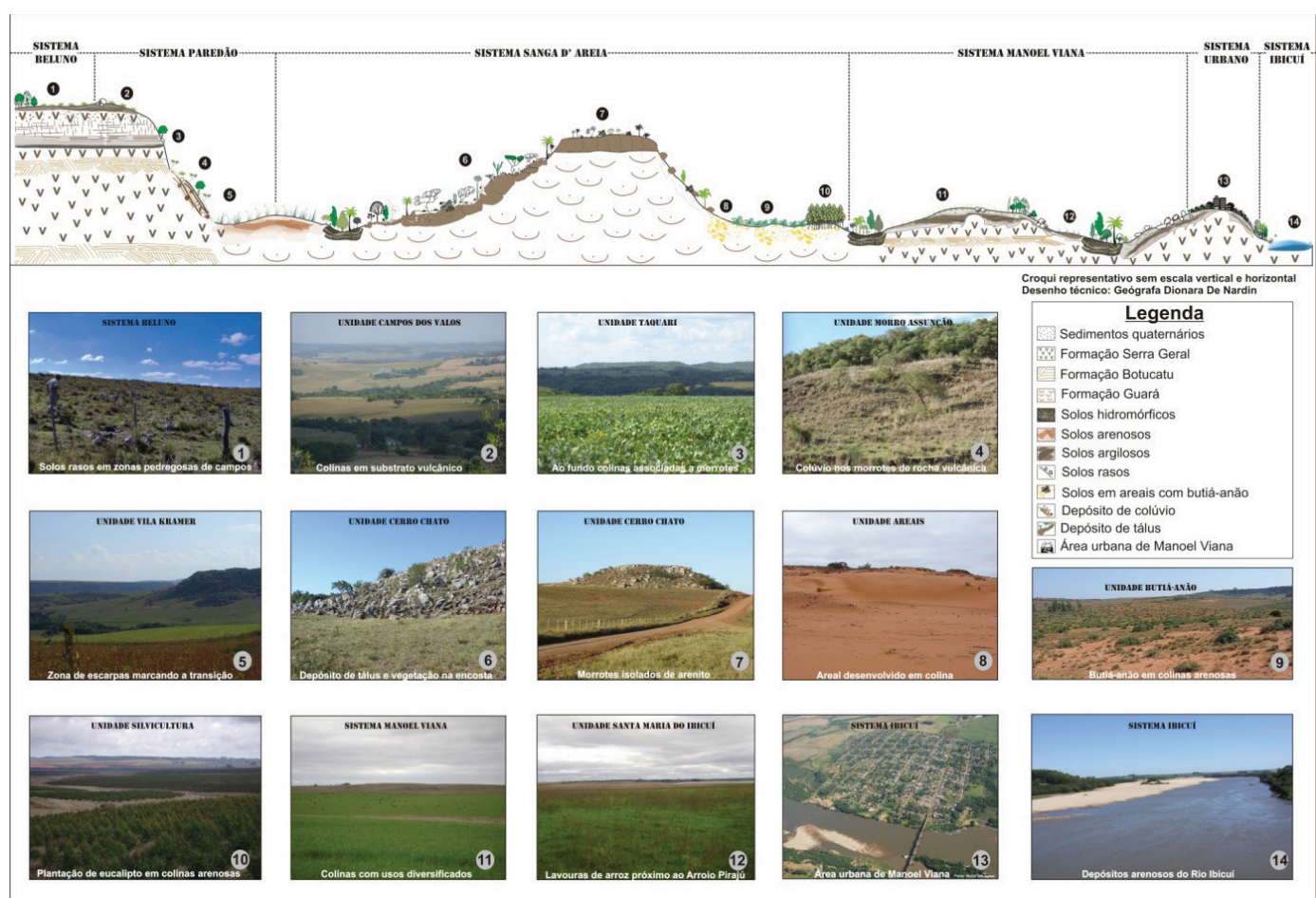

Figura 10: Croqui esquemático do zoneamento geoambiental da área de estudo. 
que condicionam e formam a geomorfologia de bacias hidrográficas do oeste do Rio Grande do Sul. As análises do uso da terra e da cobertura vegetal permitiram compreender como se espacializa o processo de ocupação da área de estudo que, associadas às demais informações, oportunizaram a identificação das zonas de fragilidade e potencialidade, necessárias para planejar o zoneamento geoambiental.

O diagnóstico apresentou aspectos marcantes do Bioma Pampa, que é um dos Biomas com menor percentual de área legalmente protegida. De acordo com o IBAMA (2006), nas áreas de ocorrência do Bioma Pampa stricto sensu - regiões da Campanha, Depressão Central, Serra do Sudeste e Missões somente $0,04 \%$ (cerca de 7.000 hectares) estão em Unidades de Conservação de Proteção Integral, e, no entanto, nenhuma federal. Este fato remete à sensação de que o desconhecimento da biodiversidade tenha favorecido o não comprometimento com a preservação de determinadas porções e, consequentemente, a provável extinção de espécies da fauna e da flora associadas a estes relictos.

Além disso, diferentemente do que vinha sendo divulgado no meio acadêmico e na imprensa desde os primeiros debates a respeito dos processos de arenização no oeste gaúcho, a pesquisa aponta que o substrato litológico mais associado à formação de areais, nos municípios de Manoel Viana e São Francisco de Assis, pertence aos arenitos friáveis de origem fluvial da Formação Guará.

Ressaltam-se importantes áreas de pesquisa dentro desse Bioma, como as do recorte deste estudo, relacionadas com os sítios arqueológicos, com a diversidade de espécies adaptadas, como a pitangasdo-campo (Eugenia arenosa), que está incluída na lista das espécies ameaçadas de extinção, segundo a Secretaria Estadual de Meio Ambiente (SEMA, 2009), e o butiá-anão (Butia lallemantii), que recentemente foi considerado espécie endêmica dos campos gaúchos, bem como as próprias formações campestres pouco conhecidas.

Ao término do estudo, acredita-se que a contribuição do SIG, através do uso de softwares, como o ArcGis e Envi, veio a acrescentar na qualidade e exatidão da metodologia de mapeamento, facilitando o zoneamento e, ao mesmo tempo, estando associada a concisos trabalhos de campo.

Conclui-se que a metodologia empregada mostrou-se eficiente para a proposta de zoneamento, pois permitiu identificar informações importantes para futuras intervenções, tanto no que diz respeito à arenização, quanto à preservação da vegetação endêmica da região. Nesse sentido, a metodologia de zoneamento apresentada pode ser aplicada em diferentes regiões, contribuindo para o planejamento mais eficaz, uma vez que permite que os investimentos possam ser aplicados de acordo com as peculiaridades de cada zona, as quais passam a ser tratadas como sistemas e unidades de planejamento.

\section{AGRADECIMENTOS}

A CAPES pela concessão da bolsa de mestrado e ao $\mathrm{CNPq}$ pelo auxílio à pesquisa com apoio financeiro (Processo n. ${ }^{\circ}$ 475765/2007-9).

\section{REFERÊNCIAS}

AMARAL, R.; ROSS, J. L. S. Cartografia Geomorfológica: O uso de Sistema de Informação Geográfica (SIG) para a confecção de cartas de fragilidade. In: SIMPÓSIO NACIONAL DE GEOMORFOLOGIA E I ENCONTRO SUL-AMERICANO DE GEOMORFOLOGIA, 5, 2004, Santa Maria. Anais... Santa Maria: UFSM, 2004.

BERTRAND, G. Paisagem e Geografia Física Global: esboço metodológico. Cadernos de Ciências da Terra, São Paulo: IG-USP, n. 13, p. 1-27. 1972.

CENDRERO, A. Uma ferramenta para a avaliação e monitoramento de unidades de mapa geoambientais: os índices de qualidade ambiental. In: Simpósio Brasileiro de Cartografia Geotécnica e Geoambiental, 5, 2004, São Carlos. Anais... São Carlos, 2004.

DE NARDIN, D. Zoneamento Geoambiental no Oeste do Rio Grande do Sul: Um estudo em bacias hidrográficas. 2009. 230 f. Dissertação (Mestrado em Geografia). Universidade Federal do Rio Grande do Sul, 2009. Disponível em: $<$ http://hdl.handle. net/10183/17897>. 
FREITAS, M. W. D. de; CUNHA, S. B. Geossistemas e Gestão Ambiental na Bacia Hidrográfica do Rio São João-RJ. In: $5^{\circ}$ SIMPÓSIO DE NACIONAL DE GEOMORFOLOGIA E $1^{\circ}$ ENCONTRO SULAMERICANO DE GEOMORFOLOGIA, RS, 2004, Santa Maria. Anais... Santa Maria, 2004.

GRECCHI, R. C. Zoneamento geoambiental da região de Piracicaba-SP, com auxílio de geoprocessameto. 1998. 132 f. Dissertação de Mestrado. Escola de Engenharia de São Carlos/USP, São Carlos. 1998.

GUERRA, A. T.; GUERRA, A. J. T. Novo Dicionário Geológico-Geomorfológico. 4 ed. Rio de Janeiro: Bertrand Brasil, 2005.

IBAMA. Instituto Brasileiro do Meio Ambiente e dos Recursos Naturais Renováveis. Parecer da Equipe Técnica do Ibama - Sobre o Zoneamento Ambiental da Atividade da Silvicultura no Rio Grande do Sul. 2006. Disponível em: <http://www.ibama.gov.br $>$. Acesso em: nov. 2008.

IBGE. Instituto Brasileiro de Geografia e Estatística. Dados socioeconômicos. Disponível em http://www. ibge.gov.br e http://www.sidra.ibge.gov.br. Acesso em 5 mar. 2009.

. Levantamento de recursos naturais do projeto RadamBrasil. Folha SH.21. Santiago e Alegrete. Rio de Janeiro, 1973.

. Projeto RadamBrasil: Geomorfologia (Folha SH-21. Santiago e Alegrete). Rio de Janeiro, 2003.

MINISTÉRIO DO EXÉRCITO. DSG - Diretoria de Serviços Geográficos. Carta Topográfica de Caraguataí. POA. Folha SH. 21-XD-I-3. Escala 1:50.000. 1977.

. DSG - Diretoria de Serviços Geográficos. Carta Topográfica de Vila Kramer. POA. Folha SH. 21-XD- I-4. Escala 1:50.000. 1977.

. DSG - Diretoria de Serviços Geográficos. Carta Topográfica de Manoel Viana. POA. Folha SH. 21-X-D-IV-1. Escala 1:50.000. 1977.
DSG - Diretoria de Serviços Geográficos. Carta Topográfica de São Francisco de Assis. POA. Folha SH. 21-X-D-IV-2. Escala 1:50.000. 1977.

. DSG - Diretoria de Serviços Geográficos. Carta Topográfica de Chalé. POA. Folha SH. 21-XC-III-3. Escala 1:50.000. 1977.

DSG - Diretoria de Serviços Geográficos. Carta Topográfica de Arroio Piraju. POA. Folha SH. 21-X-CIII-4. Escala 1:50.000. 1977.

. DSG - Diretoria de Serviços Geográficos. Carta Topográfica de Passo Novo. POA. Folha SH. 21-X-CVI- 2. Escala 1:50.000. 1977.

SEMA - Secretaria do Meio Ambiente do Estado do Rio Grande do Sul. Espécies da Flora Ameaçadas de Extinção do Rio Grande do Sul. 2009. Disponível em: http://www.sema.rs.gov.br. Acesso em: 03 de maio de 2009.

STRECK, E. V., et al. Solos do Rio Grande do Sul. Porto Alegre: EMATER/RS, 2002.

. Solos do Rio Grande do Sul. 2. ed. Porto Alegre: EMATER/RS, 2008.

SUERTEGARAY, D. M. A., et al. Atlas de Arenização: Sudoeste do Rio Grande do Sul. Porto Alegre: Secretaria da Coordenação e Planejamento, 2001. v. 1. Atlas.

TRENTIN, R. Definição de Unidades Geoambientais na bacia hidrográfica do Rio Itu.- Oeste do Rio Grande do Sul. 2007. 140 f. Dissertação (Mestrado em Geografia) - Universidade Federal de Santa Maria, 2007.

TRICART, J. Ecodinâmica. Rio de Janeiro: Fundação IBGE/SUPREN, 1977.

VERDUM, R. Approche Géographique des "Deserts" Dans les Communes de São Francisco de Assis et Manuel Viana - Etat du Rio Grande do Sul, Brésil. 1997, 211p. Tese (Doutorado em Geografia) - Université de Toulouse Le Mirail - UFR de Géographie, França, 1997. 
Zoneamento Geoambiental no oeste do Rio Grande do Sul: um estudo em bacias hidrográficas em processo de arenização Dionara De Nardin, Luís Eduardo de Souza Robaina

WILDNER, W., et al. Mapa Geológico do Estado do Rio Grande do Sul. Escala 1:750000. CPRM, Serviço Geológico do Brasil. Porto Alegre, RS. 2006.

ZUQUETTE, L. V. Análise Crítica sobre Cartografia Geotécnica e proposta metodológica para as Condições Brasileiras. 1987. 673 f. Tese (Doutorado em Geotecnia). Escola de Engenharia de São Carlos/USP, São Carlos, 1987.

ZUQUETTE, L. V.; GANDOLFI, N. Cartografia Geotécnica. São Paulo: Oficina de Textos, 2004. 